\title{
Ubiquitous mobile use: student perspectives on using the VLE on their phone
}

\author{
Damien Raftery, Institute of Technology Carlow
}

\begin{abstract}
With the rapid increase in the use of smart phones (and other mobile devices), students in Irish and international higher education institutions are increasingly accessing virtual learning environments (VLEs) using their phones via an app or their browser. This brings both welcome flexibility for the students' digital learning experiences and wider opportunities to support both asynchronous and synchronous learning in innovative ways. However challenges exist, initially regarding the functionality, user interface, reliability and speed of mobile use of the VLE (specifically via a VLE app as well as a phone browser) but also how best to empower students and lecturers to harness the potential benefits. This article explores the 2017 results of the \#VLEIreland student survey in one higher education institution, expanded to include questions about student experiences of using a VLE app. Almost all students have smart phones, with the VLE app used by 7 in 10 students surveyed and, despite the many limitations of the VLE app, two-thirds found it useful. Student comments highlighted the benefits of notifications on the student's phone and the convenience of easy, flexible access to the VLE. Barriers to the use of the VLE app included poor design and working of the app, and limitations of the student's own phone. A major implication of increasing mobile access is that the VLE design needs to be more responsive for users, that the VLE itself be fully functional and user-friendly on smart phones and the challenges to design, develop and deliver a rich functional VLE app are met. There is potential for flexible mobile access to the VLE outside of class to be complemented by increased in-class use to enrich innovative approaches to engage learners. Increased mobile VLE usage has consequences for how lecturers use the VLE; they need to be conscious of this mobile use when designing, creating and using their VLE course as well as utilising appropriate digital pedagogies.
\end{abstract}

Irish Journal of Technology Enhanced Learning Ireland, 2018. (C) 2018 Raftery, D. The Irish Journal of Technology Enhanced Learning Ireland is the journal of the Irish Learning Technology Association, an Irishbased professional and scholarly society and membership organisation. (CRO\# 520231) http://www.ilta.ie/. This is an Open Access article distributed under the terms of the Creative Commons Attribution 4.0 International License (http://creativecommons.org/licenses/by/4.0), allowing third parties to copy and redistribute the material in any medium or format and to remix, transform, and build upon the material for any purpose, even commercially, provided the original work is properly cited and states its license. 


\section{Introduction}

VLEs provide a stable base ... (Risquez et al, 2013, p.106)

As can be seen from the articles in this special issue (Ryan \& Risquez, 2018; Raftery \& Risquez, 2018), students both frequently use the VLE and maintain broadly positive attitudes to its use, finding it helpful to their studies. The predominate use of the VLE remains as a curated repository for class notes and slides, links to videos, websites and other learning resources, and one-way communication via announcements. Substantial use of assignment submission, grading and sharing of marks and feedback is complemented by some use of online quizzes, discussion boards and other VLE tools.

This is mirrored internationally, with US commentary that the VLE has been "has been highly successful in enabling the administration of learning but less so in enabling learning itself" (EDUCAUSE, 2015, p.2). Seery (2015) develops this, pointing out that using VLEs to support student learning (as opposed to dissemination of notes and managing classes) is "the exception rather than the rule". Indeed he argues for the removal of the dependence on the VLE, "a catch-all den of discontent". So, as Weller (2007) memorably summed this up over a decade ago, is the VLE dead? Feldstein (2014) points out that the VLE is as it is because this is how the majority of academics want it to be, with Rees (2015) commenting that academics would not continue to use by choice a VLE if they were trained to teach online effectively.

Following a summary of research methods, this article presents and discusses an analysis of students' experiences of a VLE, and specifically of a VLE app, in one higher education institution in Leinster, Ireland. This is placed in context from previous local iterations of \#VLEIreland student surveys ${ }^{1}$. Prior to conclusions, the findings are discussed along with other research and some implications are drawn. The discussion will also explore the potential for the flexible mobile access to the VLE outside of class valued by students to be complemented by increased synchronous in-class use to engage learners. This discussion is in the context of the almost ubiquitous student access to mobile devices (RTE, 2017), wi-fi (O'Rourke, 2017, p.17) and VLE apps (ibid, p.18); thus there is the potential for the VLE to survive and thrive as an app to contribute to meaningful student learning in innovative ways.

\section{Methods}

The main analysis presents the responses to a survey of students at a higher education institute in Leinster, Ireland carried out in January 2017. Context is provided by analysis of previous surveys at the same higher education institute.

Traditionally the main access to the VLE was from desktop PCs on campus, either in openaccess areas or in computer labs. At the inception of the \#VLEIreland Survey, the flexible use of the VLE was initially focused on off-campus access from home and internet cafes. In 2011 questions included use from laptops and mobile devices, then in 2013 specific mention of mobile phones and tablet devices. In 2015 a question was added gauging student attitude to the on-campus wi-fi coverage. In the most recent survey in January 2017, this was expanded with a section on the mobile use of the VLE and specifically use of a VLE app, and included some open-ended opinion questions.

\footnotetext{
${ }^{1}$ I would like to acknowledge the valuable contributions of all the \#VLEIreland collaborators (Cosgrave et al, 2013 and Risquez et al., 2013).
} 
This article explores the 890 responses of fulltime students studying on campus during the day. The response rate is $21 \%$, a slightly lower rate than previous iteration of the survey (the January 2015 survey had 1,066 respondents with a response rate of 25\%; 777 respondents in April 2013, 20\%; and 478 respondents in April/May 2011, 14\%). Note as the survey was administered online, the sample is self-selecting leading to potential sample bias with nonresponses systematically differing from those who responded (Gorard, 2013, p.88). In this article, percentages are calculated out of those who responded to the question. These limitations are a caveat to the interpretation and generalisability of the findings presented.

\section{Findings}

\subsection{General use of the VLE in 2017}

The general findings of the 2017 survey strongly mirror those of the previous years. Most of the students surveyed are positive about the VLE and use it regularly. 93\% of respondents use the VLE regularly: $61 \%$ of respondents use the VLE daily, with a further $33 \%$ using it a few times a week. 92\% of respondents agree that systems like the VLE are helpful whilst $81 \%$ agree that the VLE is easy to use. Almost all respondents use the VLE to some extent, with over two in three students having all or most of their coursework in the VLE: $21 \%$ of respondents had all, with $48 \%$ having most, $13 \%$ with about half, $16 \%$ with some and $2.1 \%$ (19 students) with none.

The findings confirm previous results that the VLE's most popular use is still as a content management tool, with almost all respondents accessing lecture notes/handouts - see figure 1. However there is considerable use of, and apparent positive disposition of many students to, the use of online resources, assignment submission, Turnitin and online quizzes. When asked what are the reasons for using the VLE, most respondents find it useful to view class announcements $(87 \%)$ and get copies of lecture notes/handouts $(95 \%)$ and other course documents (85\%), with a majority also finding the VLE useful for Reading Lists and recommended online resources (65\%). $37 \%$ of respondents do not use Recommended videos, screencasts and podcasts, but of those that do, $72 \%$ find them useful.

Substantial proportions of students find the VLE useful for submitting assignments (82\%) and Turnitin (77\%), along with some use of online quizzes and discussion boards. $45 \%$ of respondents do not use online quizzes, but of those that do, $66 \%$ find them useful. Similary $47 \%$ of respondents do not use Online Discussion, but of those that do, $50 \%$ find them useful. In open comments, students report using the VLE to view grades and as a gateway to other services, such as email, library, past papers and timetables.

Students believe that the VLE gives them more access to the lecturers, but not their fellow students. Specifically $71 \%$ of respondents agree that the VLE gives them more access to their lecturers, with $11 \%$ disagreeing. However, only $16 \%$ of respondents agree that the VLE gives them more access to their classmates, with $51 \%$ disagreeing. 


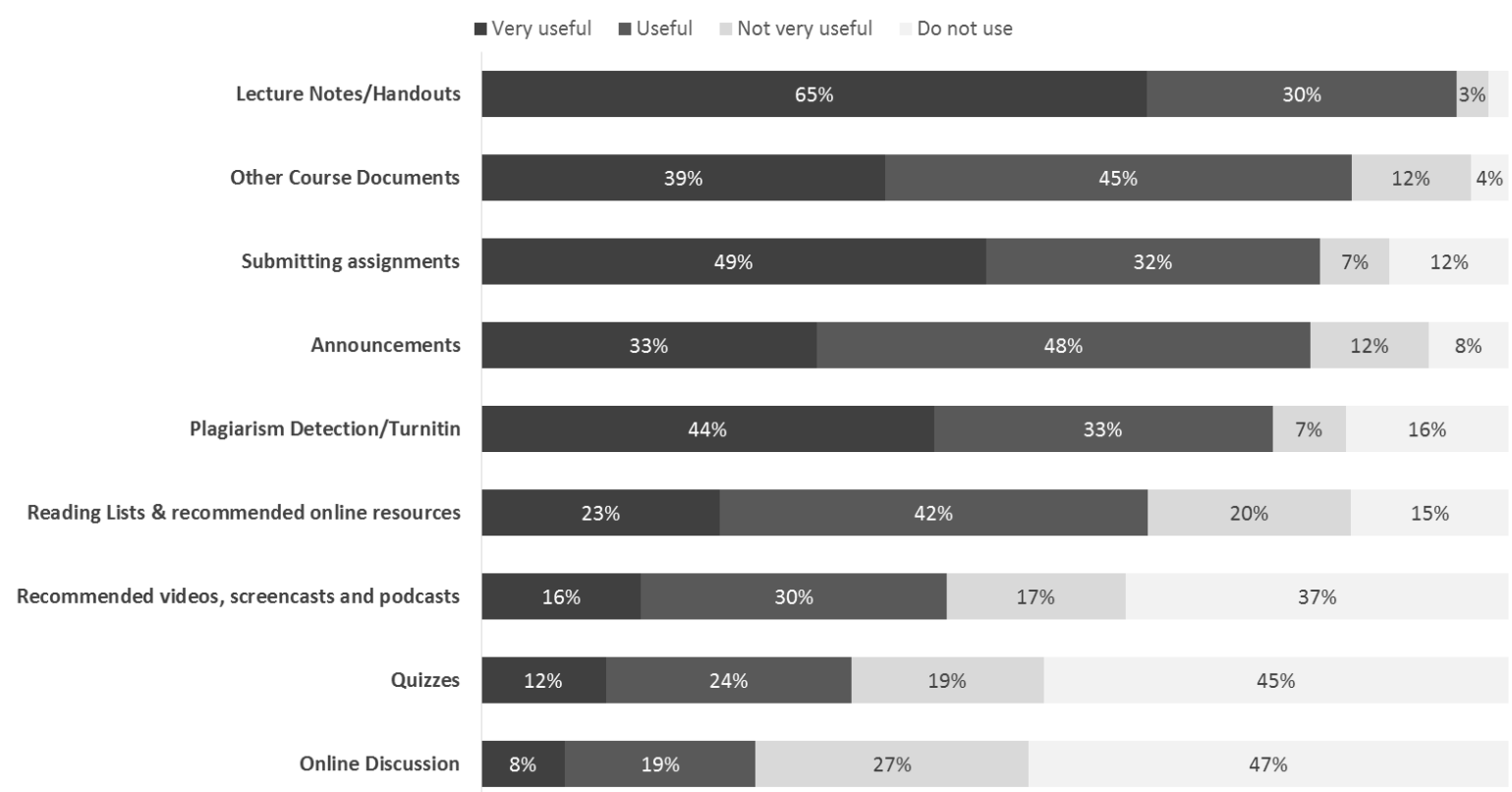

Figure 1: Student ratings of VLE features in 2017.

The students who responded to the survey were positive about the current use of the VLE on their programme and would welcome more use of it. $61 \%$ of respondents agree that they would like their lecturers to make more use of the VLE on their programme (6\% disagree). $59 \%$ agree that there is good use of the VLE by lecturers on their programme (14\% disagree). Even of those who disagree that there is good use of the VLE, $82 \%$ of these respondents would like more use of the VLE.

\subsection{The rise of the phone: mobile access to the VLE}

I can learn at home, even in bed (student comment).

As can be seen in Figure 2 below, consistently in student surveys in 2011, 2013, 2015 and 2017 over 9 in 10 respondents access the VLE from home. With a little more variation, about half of students access the VLE from laptops on campus with a little more from open-access PCs. However the substantial growth, from a base of $16 \%$ for all mobile devices in 2011 , is for mobile phone access to the VLE to $75 \%$ in 2017 with $22 \%$ of respondents using tablet devices.

The increasing use of mobile devices, in general and specifically for using VLE via mobile phones and tablets, has contributed to greater demands for good wi-fi on campus. Students had mixed responses when asked to respond to the statement "The wi-fi coverage on campus is good", with $44 \%$ agreeing, $29 \%$ neutral and $27 \%$ disagreeing (this is slightly more positive than in 2015: $38 \%$ agreeing, $27 \%$ neutral and 35\% disagreeing) $)^{2}$.

\footnotetext{
${ }^{2}$ Note that the 2017 survey was before a major upgrade to campus wi-fi.
} 
Vol 3, Issue 2, 2018

In $2017,88 \%$ of respondents agree that they have adequate access to the web (computer, bandwidth) from outside college, with $4 \%$ disagreeing. This is similar to findings from previous years, with just under 9 in 10 students consistently agreeing.

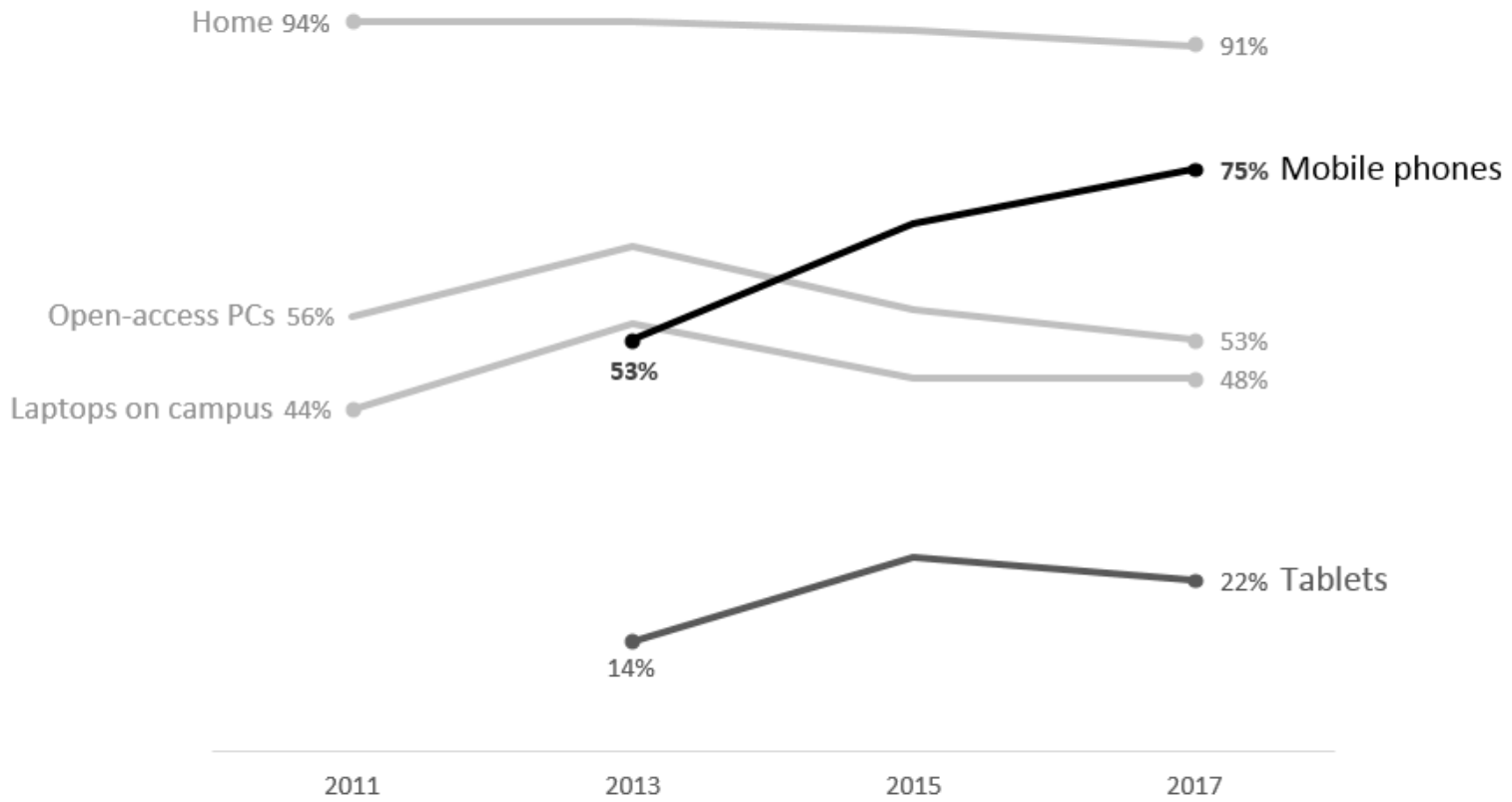

Figure 2: Substantial growth in mobile phone access to the VLE (note in 2011, there was $16 \%$ access from mobile devices).

\subsection{The VLE app used by 7 in 10 students surveyed}

The app is so handy. I can access lecture notes anywhere at any time. I also receive notifications about new material or when a new assignment has been up. It is also a way of communication between the lecturers and students. I love the app (student comment).

Almost all, 98\%, of respondents own a smart phone. Of these smart phone users, $72 \%$ of indicating that they have installed the VLE app. Despite the limitations of the VLE app as of January 2017 (there was a major upgrade of the app in the summer of 2017) of those that responded to the statement "The [VLE] app is useful", two thirds agreed as can be seen in Figure 3 (with $14 \%$ in disagreement).

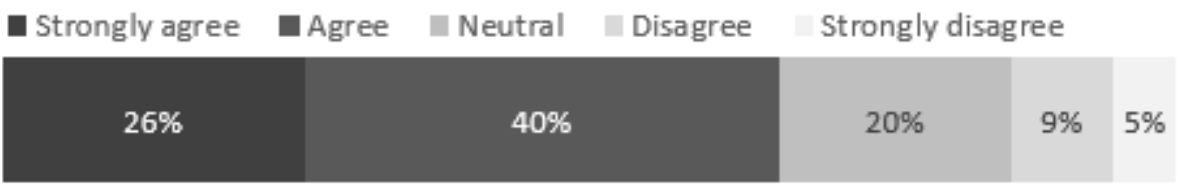

\section{Figure 3: Substantial agreement that the VLE app is useful.}

There were 442 meaningful responses to the open-ended question "What aspect of the [VLE] app do you find most useful?" Most comments related to the benefits of notifications straight to the student's phone (170), the access to lecture notes/slides (122) and the convenience of 
easy, flexible access to the VLE (124). Some students value the ability to instantly access grades (43), and to timetables and notifications of class changes or cancellations (26).

Selected student comments:

- Very mobile-friendly and easy to use

- Makes it easier for me to keep up with my courses by letting me access them whenever and wherever I want

- That I always have my phone on me therefore always have access to [VLE]

- Notifications about announcements I would usually miss if I did not have the app, such as when a lecture is cancelled/postponed or a request to bring specific set of notes to a lecture

- Easy to bring up notes in class

- Information is easily accessible and easy to find

- Can access notes anywhere, makes studying outside of college hours easier

- Easy to access and navigate

- [VLE] desktop does not display well on smartphone web browser. App much better

For the open-ended question "Installed the [VLE] App: If No, why not?" there were meaningful 195 responses. The main reasons given were poor design and working of the app (35 responses) and limitations of phone, specifically lack of memory (34). Some students did not know about the app (27), didn't know how to install (4) or had problems with installing (8). Other frequent responses included a preference for using the VLE on other devices (25) or via the browser on the phone (16). Some indicated that they had no need of the app (23), sometimes because the VLE is not used a lot on their programme (7). A few indicated that they had an old phone (4), lacked wi-fi on campus (3) or wished to keep their phone separate from their studies (3).

- It's not on my smartphone, so am not aware when I receive messages. Hence I don't think of checking it or use it as often. How do I put it on my phone?

- Unreliable, often crashes and it is hard to navigate through

- You would get a notification but it would not open in the app, then the app would crash. Good for alerts to say something new is posted but not to see what that new content is

- Too hard to install and takes up a lot of space

- I downloaded it but it's difficult to use

- My phone is too small to view any notes posted on [VLE]

- Wi-fi in campus is not good enough to access it on my phone in campus

- Because I prefer access to [VLE] with my laptop. Receiving notifications on your phone can be stressful sometimes

- No real push to download this. What is the benefit?

There were 242 meaningful responses to the open-ended question "Is there any change that you would recommend to improve your [VLE] app experience?" The main focus of comments were on the need to improve the user interface (78), reliability (46) and speed (44). Some respondents wanted easier access to grades (15) and timetable (5), and the design and features to be similar to the full web version (13). A few suggested more help / orientation for new users.

- Make it easier to use

- Make it more similar to the desktop version

- Many functions do not work or take you to the desktop version

- When you get a notification and you click on it, you only get brought to the main menu and not to the notification 
- Sometimes a lot of notifications come through at the same time, making it less likely for me to check them all as sometimes I get multiple notifications for the same thing

- Add more features that are available on the web version but not the app

- I don't stay logged in and have to re-enter my login every time I open it

- Course announcement isn't shown as a category in each course. I have to access via homepage which is linked back to website and not very presentable

- Make every file mobile friendly

These findings, including the comments from students, will be discussed in the next section.

\section{Discussion}

Online, mobile, and blended learning are foregone conclusions. If institutions do not already have robust strategies for integrating these now pervasive approaches, then they simply will not survive. An important step is tracking how these models are actively enriching learning outcomes (Adams Becker et al., 2017).

In 2015 for Irish higher education, the time-to-adoption for bring your own device (BYOD), flipped classroom and mobile learning were all identified as one year or less (Johnson, Adams Becker, Estrada \& Freeman, 2015). More recently in 2017 for international higher education, the time-to-adoption of mobile learning was also stated as one year or less (Adams Becker et al., 2017). This report also highlighted Improving Digital Literacy as a solvable challenge, Advancing Digital Equity as a difficult challenge and Redesigning Learning Spaces as a mid-term trend (ibid,2017). There are major strategic and practical implications of widespread use of mobile devices for learning, taking into account also the specific mobile use of the VLE on phones (via a VLE app or mobile browser) to support teaching and learning. These include redesign of both formal classrooms and informal learning spaces, and requirements for supporting campus infrastructure such as wi-fi.

Almost all students have smart phones, with the VLE app used by 7 in 10 students surveyed and two-thirds finding it useful. The themes from the student comments highlighted the benefits of notifications on the student's phone and the convenience of easy, flexible access to the VLE, specifically to lecture notes, grades and other resources. Barriers to the use of the VLE app included poor design and working of the app and limitations of the student's own phone. There were many suggested areas for improvement, focusing mainly the VLE app itself: improve the user interface, reliability and speed with features comparable to the web interface.

There is potential for flexible mobile access to the VLE outside of class to be complemented by increased in-class use to enrich innovative approaches to engage learners. Through using the VLE app (or mobile browser) previously underused VLE features such as online discussions and quizzes may enable active learning in the classroom. The current VLE app integrates discussion boards prominently, an opportunity to address that about half of students surveyed disagreed that the VLE gave them more access to their classmates (only $16 \%$ agreed). Despite its user-friendliness, the technical limitations of not being able to format text, add hyperlinks, embed images or videos, may severely limit the usefulness in the classroom.

Students being able to complete formative, and possibly summative, online quizzes on their phones brings multiple advantages: engaging for students, a support for active learning via 


\section{Raftery}

the testing effect and spaced practice (Brown et al, 2014, Didau 2015), and a knowledge check on work required prior to class (including supporting flipped learning approaches). As the quiz is within the VLE, the students' marks and attempts are recorded in the grade centre, giving potentially valuable feedback to the lecturer on areas of general difficulty plus possibly identifying individual students who are struggling. An institutional benefit that may accrue is that that the data may be valuable in a learning analytics system. As the VLE is an official institutional system, the lecturer does not need to deal with any General Data Protection Regulation (GDPR) issues that may arise with third-party systems. However, for online quizzes to be useful in the classroom, the student experience needs to be such that the technology is sufficiently user-friendly so that the students' focus is on the subject matter being assessed and not on any limitations of the interface. Experience of a limited pilot of a formative in-class online VLE quiz late 2017 is that although almost all students were able to complete the quiz on their phone (a small number experienced phone and wi-fi issues), there were a number of limitations of the VLE app itself. In particular, in the VLE app but not the VLE via a browser on the phone, an image inserted in the question nor a mathematical expression containing a superscript showing a power were not displayed properly. Also many students submitted after only answering one question, partly because of there being no warning in the VLE app that not all questions had been completed unlike the experience of using the VLE via a browser.

The experience for students of using the VLE app or mobile browser for active learning in class - particularly using discussion boards, taking online quizzes, sharing output of group discussions or individual explorations by uploading images and multimedia, adding reflections to the journal, ... - needs to be easy and seamless so the focus remains clearly on the learning tasks and not on technical frustrations. To be useful, the VLE app needs to offer rich features that support learning.

\section{Conclusion}

... the spaces we create for fostering learning experiences matter, and that one size cannot fit all. Therefore, teachers and students should have a great deal of control in shaping their learning environments. To the degree that it is possible, technology platforms should get out of the way and avoid dictating choices. This is a really hard thing to do well in software, but it is a critical guiding principle for virtual learning environments (Feldstein, 2014).

Despite the many limitations of the current VLE app, the students surveyed both use and value the flexible access to the VLE on their smart phone. A major implication of increasing mobile access is that the VLE design needs to be more responsive for users, that the VLE itself be fully functional and user-friendly on small touch screens. This increased mobile VLE usage has consequences for how lecturers use the VLE and they need to be conscious of this mobile use when designing, creating and using their VLE course as well as digital pedagogies. Institutions need to support students' digital literacy and meet the challenges of digital equity.

Important issues to explore include: mobile use of the VLE to enable active approaches to learning; data analytics of mobile access of VLE; mobile use of VLE to enable flexible submissions including uploading of images/audio/video and contributions to discussion boards in class; and, using the VLE app for formative and summative flexible quizzes in class. 
Irish Journal of Technology Enhanced Learning

Vol 3, Issue 2, 2018

The VLE continues to survive and evolve, with the stable base of curated access to lecture notes and other learning resources complemented by assignment submission and communications. For the VLE to thrive, it needs to enable and enrich student engagement and learning outcomes - active learning approaches in well-designed spaces and flexible fullfunctionality via responsive, well-designed interfaces. As Smithers (2016) rightly points out, we need to "think of the experiences that we want as learners and educators". 


\section{References}

Adams Becker, S., Cummins, M., Davis, A., Freeman, A., Hall, Giesinger, C., \& Ananthanarayanan, V. (2017). NMC Horizon Report: 2017 Higher Education Edition. Austin, Texas: The New Media Consortium. Retrieved from https://www.nmc.org/publication/nmc-horizon-report-2017-higher-education-edition/

Brown, P.C., Roediger, H.L., McDaniel, M.A. (2014). Make It Stick: The Science of Successful Learning. Harvard University Press: Cambridge, MA, United States.

Cosgrave, R., Risquez, A., Raftery, D., Logan-Phelan, T., Costello, E., Harding, N., Palmer, M., McAvinia, C. \& Farrelly, T. (2013). The VLE Usage Survey Five Years in: Overview of Findings and Future Directions. EdTech 2013, research paper presentation, University College Cork, 30-31 May.

Didau, D. (2015). What If Everything You Knew about Education Was Wrong? Crown House Publishing: Carmarthen, Wales

EDUCAUSE (2015). The Next Generation Digital Learning Environment: A Report on Research. Retrieved from https://library.educause.edu/ /media/files/library/2015/4/eli3035pdf.pdf

Feldstein, M. (2014). Dammit, the LMS. Retrieved from http://mfeldstein.com/dammit-lms/

Gorard, S. (2013). Research Design: Creating Robust Approaches for the Social Sciences. London: SAGE.

Johnson, L., Adams Becker, S., Estrada, V., \& Freeman, A. (2015). NMC Horizon Report: 2015 Higher Education Edition. Austin, Texas: The New Media Consortium. Retrieved from https://www.nmc.org/publication/nmc-horizon-report-2015-higher-education-edition/

O’Rourke, K. C. (2017). Ireland's Higher Education Technical Infrastructure: A review of current context, with implications for teaching, and learning enhancement. Dublin: National Forum for the Enhancement of Teaching and Learning. Retrieved from https://www.teachingandlearning.ie/wp-content/uploads/2017/12/Final-Infrastructure-reportwith-doi-web-ready.pdf

Raftery, D. and Risquez, A. (2018): Engaging students through the VLE: comparing like with like using the \#VLEIreland student survey. [Special Issue, McAvinia and Risquez]. Irish Journal of Technology Enhanced Learning, 3(2), 24-34.

Risquez, A., McAvinia, C., Raftery, D., O’Riordan, F., Harding, N., Cosgrave, R., LoganPhelan, T. \& Farrelly, T. (2013). An investigation of students' experiences of using virtual learning environments: implications for academic professional development. In C. O'Farrell \& A. Farrell (Eds.). Emerging Issues in Higher Education III: from capacity building to sustainability. Athlone: EDIN (Educational Developers in Ireland Network). Retrieved from http://www.edin.ie/?page_id=112

Ryan, D and Risquez, A (2018): 'Lessons Learnt': the student view in the \#VLEIreland project [Special Issue, McAvinia and Risquez]. Irish Journal of Technology Enhanced Learning, 3(2), 1-10. 
Irish Journal of Technology Enhanced Learning

Vol 3, Issue 2, 2018

Rees, J. (2015) Cut the professor a check and walk away. Retrieved from http://moreorlessbunk.net/technology/cut-the-professor-a-check-and-walk-away/

RTE (2017). 90\% of Irish population have access to smartphone, survey finds. Retrieved from https://www.rte.ie/news/2017/1205/925007-smartphone/

Seery, M. (2015). We need to talk about VLEs. RSC Blog, Retrieved from http://www.rsc.org/blogs/eic/2015/06/vle-virtual-learning-environment

Smithers, M. (2016). Why University Learning Management Systems are the temporary classrooms of today. Retrieved from http://www.masmithers.com/2016/06/why-universitylearning-management-systems-are-the-temporary-classrooms-of-today/

Weller, M. (2007). The VLE/LMS Is Dead. Retrieved from

http://nogoodreason.typepad.co.uk/no_good_reason/2007/11/the-vlelms-is-d.html 